\title{
Penyuluhan Kewirausahaan pada Kelompok PKK dalam Mendorong Pelaku UMK Desa Rambu-Rambu
}

\author{
Rola Pola Anto ${ }^{*}$, La Ode Sahili ${ }^{2}$, Sitti Rahmatyah ${ }^{3}$, Risman Togala \\ ${ }_{1,2,3}$ Universitas Lakidende, Unaaha, Indonesia; ${ }^{4}$ Universitas Sulawesi Tenggara, Kendari, Indonesia \\ ${ }^{*}$ Corresponding Author: rola.polaanto70@gmail.com
}

\begin{abstract}
Info Artikel
Diterima: $17 / 02 / 2022$

Direvisi: 20/02/2022

Disetujui: 24/02/2022

Abstract. Rambu-Rambu Village is one of the villages in Laeya District, South Konawe Regency. RambuRambu Village has potential human resources, potential for agricultural and plantation products that can support entrepreneurial development. The problem faced by the community, especially the Family Welfare Empowerment Group (FWE)) is that they do not yet have the knowledge and understanding of entrepreneurship because they have never received entrepreneurship counseling from the government and universities. To overcome this problem, it is important to conduct counseling through the Institute for Research and Community Service (IRCS). The purpose of entrepreneurship counseling is to convey information to the FWE group so that they have knowledge, understanding and increase the participants' insight on how to do entrepreneurship. The method of implementing the extension is through the stages of observation and site survey, coordinating with the village government, preparing the location for the extension event, and providing tools or facilities and infrastructure, then carrying out counseling through lectures and questions and answers. Entrepreneurship counseling was held at the Rambu-Rambu Village Hall with a total of 42 participants. The results of the extension activities showed that the extension materials delivered by the extension team were very useful for the FWE group because it could provide motivation, could increase knowledge and understanding of entrepreneurship and could encourage the FWE group to be more creative and innovative in taking micro and small business opportunities. From the results of the question and answer, it was also revealed that after completing the entrepreneurship counseling activities, it is better to continue the beginner entrepreneur training activities for the practice of making micro and small business products.
\end{abstract}

Keywords: Counseling, Entrepreneurship, Micro small business

\begin{abstract}
Abstrak. Desa Rambu-Rambu merupakan salah satu desa di Kecamatan Laeya Kabupaten Konawe Selatan. Desa Rambu-Rambu memiliki potensi sumber daya manusia, potensi hasil pertanian dan perkebunan yang dapat mendukung pengembangan kewirausahaan. Masalah yang dihadapi masyarakat khususnya kelompok pemberdayaan kesejahteraan keluarga (PKK) adalah belum memiliki pengetahuan dan pemahaman tentang cara berwirausaha karena belum pernah mendapatkan penyuluhan kewirausahaan dari pemerintah dan perguruan tinggi. Untuk mengatasi masalah tersebut penting dilakukan penyuluhan melalui Lembaga Penelitian dan Pengabdian Masyarakat (LPPM). Tujuan penyuluhana kewirausahaan adalah untuk menyampaikan informasi kepada kelompok PKK agar memiliki pengetahuan, pemahaman dan meningkatkan wawasan peserta cara berwirausaha. Metode pelaksanaan penyuluhan melalui tahapan pengamatan dan survey lokasi, koordinasi dengan pemerintah desa, menyiapkan tempat acara penyuluhan, dan menyediakan alat atau sarana dan prasarana, kemudian melaksanakan penyuluhan melalui ceramah dan tanya jawab. Penyuluhan kewirausahaan dilaksanakan di Balai Desa Rambu-Rambu dengan jumlah peserta sebanyak 42 orang. Hasil kegiatan penyuluhan menunjukkan bahwa materi penyuluhan yang disampaikan tim penyuluh sangat bermanfaat bagi kelompok PKK karena dapat memberi motivasi, dapat meningkatkan pengetahuan dan pemahaman cara berwirausaha serta dapat mendorong kelompok PKK untuk lebih kreatif dan inovatif dalam mengambil peluang usaha mikro dan kecil. Dari hasil tanya jawab juga terungkap bahwa setelah selesai kegiatan penyuluhan kewirausahaan sebaiknya lanjutkan kegiatan pelatihan wirausaha pemula untuk praktek pembuatan produk usaha mikro dan kecil.
\end{abstract}

Kata Kunci: Penyuluhan, Kewirausahaan, Usaha Mikro Kecil.

How to Cite: Anto,R.P., Sahili, L. O., Rahmatuah, S., \& Togala, R. (2022). Penyuluhan Kewirausahaan pada Kelompok PKK dalam Mendorong Pelaku UMK Desa Rambu-Rambu. Prima Abdika: Jurnal Pengabdian Masyarakat, 2(1), 83-89. https://doi.org/10.37478/abdika.v2i1.1707 licensed under a Creative Commons Attribution-ShareAlike 4.0 International License.

\section{Pendahuluan}

Desa Rambu-Rambu Kecamatan Laeya Kabupaten Konawe Selatan adalah salah satu wilayah pedesaan yang memiliki potensi desa yang cukup baik dengan kondisi demografi yang majemuk. Kondisi warga masyarakat memiliki tingkat kesejahteraan yang tidak merata (masih ada yang masuk 
kategori miskin). Penduduk Desa Rambu-Rambu berjumlah 1.237 jiwa atau $301 \mathrm{KK}$, dengan jumlah anggota pemberdayaan kesejahteraan keluarga (PKK) sebanyak 301. Warga desa atau anggota PKK Desa Rambu-Rambu merupakan sumber daya yang sangat potensial dan dapat berpartisipasi dalam pengembangan usaha mikro dan kecil (UMK). Partisipasi perempuan dalam pengkondisian yang menguntungkan keluarga besar merupakan keajaiban umum yang telah berlangsung lama dan menjangkau seluruh sistem sosial yang menguntungkan masyarakat (Tuwu, 2018).

Kondisi warga masyarakat Desa Rambu-Rambu belum mampu mengembangkan UMK untuk meningkatkan pendapatan keluarga. Sebagian besar warga masyarakat hanya mengandalkan dari hasil pertanian dan perkebunan. Potensi hasil pertanian dan perkebunan cukup tersedia namun belum dapat dimanfaatkan melalui UMK secara optimal untuk peningkatan pendapatan keluarga. Warga masyarakat atau anggota PKK belum mampu mengambil peluang usaha, kurang kreatif dan kurang inovatif. Penyebab utama belum optimalnya pengembangan UMK adalah minimnya akses informasi terkait kompetensi kewirausahaan, minimnya pengetahuan dan keterampilan serta belum adanya pemahaman tentang cara berwirausaha, sehingga anggota PKK tidak mampu membuat perencanaan usaha (business plan) yang akan dikembangkan. Zimmerer menjelaskan bahwa faktor yang menyebabkan wirausaha gagal dalam menjalankan usaha barunya yakni tidak kompeten dalam manajerial dan tidak kompeten atau tidak memiliki kemampuan dan pengetahuan mengelola usaha (Krisnaldy, 2021).

Sehubungan hal tersebut maka motivasi dan kompetensi kewirausahaan warga desa atau anggota PKK Desa Rambu-Rambu penting untuk dibangkitkan agar keinginan untuk berwirausaha dapat timbul seiring dengan kemajuan dunia UMK saat ini. Tentu hal sejalan dengan konsep kewirausahaan adalah suatu nilai yang diwujudkan dalam perilaku yang dijadikan sumberdaya, tenaga penggerak, tujuan, siasat, kiat, proses dan hasil bisnis (Krisnaldy, 2021). Kewirausahaan adalah suatu proses kreativitas dan inovasi yang mempunyai resiko tinggi untuk menghasilkan nilai tambah bagi produk yang bermanfaat bagi masyarakat dan mendatangkan kemakmuran bagi wirausahawan (Yonaldi, 2018). Kewirausahaan itu dapat dipelajari walaupun ada juga orang-orang tertentu yang mempunyai bakat dalam hal kewirausahaan. Dengan menumbuhkan semangat wirausaha, maka dapat meningkatkan sumberdaya ekonomi. Eddy Soeryanto Soegito bahwa kewirausahaan adalah usaha kreatif yang dibangun berdasarkan inovasi untuk menghasilkan sesuatu yang baru, memiliki nilai tambah, memberi manfaat, menciptakan lapangan kerja dan hasilnya berguna bagi orang lain (Vernia, 2018). Kewirausahaan adalah proses dinamik untuk menciptakan tambahan. kemakmuran. Tambahan kemakmuran ini diciptakan oleh individu wirausaha yang menanggung resiko, menghabiskan waktu dan menyediakan berbagai produk barang dan jasa (Alma, 2014).

Upaya yang harus ditemouh untuk mengatasi minimnya akses informasi terkait kewirausahaan dan minimnya anggota PKK yang memiliki pengetahuan cara wirausaha, tidak kreatif dan tidak inovatif dalam memanfaat sumber daya yang tersedia, maka perlu dilakukan penyampaian informasi melalui penyuluhan kewirausahaan secara langsung dan terbuka agar wawasan anggota PKK dapat terbuka dan termotivasi untuk berani berusaha pada level UMK. Hal hasil studi bahwa untuk meningkatkan 
pengetahuan dan pemahaman pelaku usaha industry kecil dan menengah maka perlu dilaksanakan kegiatan pelatihan kewirausahaan bagi industri kecil menengah (Yonaldi, 2018).

Pelaksanaan penyuluhan kewirausahaan pada kelompok PKK bertujuan untuk mendorong anggota PKK di Desa Rambu-Rambu untuk lebih berperan aktif dalam meningkatkan pendapat keluarga, memberikan wawasan pemngetahuan dan informasi secara praktis serta memberi wawasan pengetahuan dan keterampilan cara berwirausaha dengan memanfaatkan berbagai peluang usaha. Penyuluhan kewirausahaan dapat mendorong terciptanya produk-produk UMK yang baru untuk menopang perekonomian dan kesejahteraan keluarga. Hal ini sejalan hasil studi bahwa sebagai solusi yang harus ditempuh agar ibu-ibu PKK dapat berwirausaha yakni dengan cara memberikan motivasi dan pelatihan kepada ibu-ibu PKK yang ada di lingkungan tersebut agar ibu-ibu PKK mampu menambah keterampilannya dalam berwirausaha dan mampu memberikan informasi secara berkesinambungan kepada ibu-ibu yang ada di lingkungannya atau bahkan para ibu-ibu PKK mampu menciptakan UMKM sehingga mampu menyerap tenaga kerja di sekitar lingkungan agar bisa memiliki penghasilan sendiri (Apriani, 2021).

Penyuluhan kewirausahaan pada anggota PKK sebagai upaya untuk mengedukasi, memotivasi, menciptakan dan menumbuhkan wirausaha pemula yang memiliki jiwa kreativitas dan inovatif serta beperan aktif dalam meningkatkan perekonomian Desa Rambu-Rambu. Mengklasifikasikan wirausahawan wanita menjadi tiga urutan, mendapatkan wirausaha karena hanya ada kesempatan, dipaksa, dan dirancang dengan sengaja atau benarbenar ingin menjadi wirausaha (Tambunan, 2012). Motivasi membuat anggota kelompok ingin membangun kemampuan, energi dan waktu mereka untuk memenuhi tanggung jawab dan kewajiban mereka untuk mencapai hal-hal yang berbeda (Siagian, 2012). Pelaksanaan penyuluhan kewirausahaan salah satu upaya untuk mendorong peningkatan kesejahteraan masyarakat Desa Rambu-Rambu dan untuk menyukseskan program "Desa Maju Konsel Hebat"

\section{Metode Pelaksanaan}

Pelaksanaan kegiatan penyuluhan kewirausahaan pada kelompok PKK Desa Rambu-Rambu dimulai dari tahap pengamatan atau survey untuk mengetahui kondisi sosial terkait pengembangan kondisi UMK di Desa Rambu-Rambu. Selanjutnya melakukan koordinasi dan menyampaikan surat penyampaian izin lokasi penyuluhan kewiraushaan dari LPPM pada pemerintah desa (kepala desa). Tahapan berikutnya menyiapkan tempat acara di Balai Desa Rambu-Rambu, menyiapkan kursi dan meja, sound system, dan perlengkapan lainnya. tahapan berikutnya adalah pelaksanaan penyuluhan kewirausahaan yang dimulai dengan pembukaan, penyampaian materi kewirausahaan oleh tim dari LPPM Universitas Lakidende. Metode penyampaian materi dengan cara ceramah dan tanya jawab pada peserta untuk memberikan solusi dari masalah yang dihadapi peserta. Kegiatan penyuluhan juga didukung dari mahasiswa untuk membantu selama pelaksanaan acara dan evaluasi kegiatan penyuluhan diakhir acara.

\section{Hasil dan Pembahasan}

Kegiatan penyuluhan dilaksanakan pada hari Sabtu 4 Desember 2021, waktu pelaksanaan mulai pukul 08.30 sampai 11.00 wita di Balai Desa 
Rambu-Rambu Kecamatan Laeya. Pelaksanaan penyuluhan dihadiri Kepala Desa Rambu-Rambu beserta pengurus dan anggota PKK dari Dusun I, II dan III. Peserta yang hadir dalam penyuluhaan sebanyak 42 orang anggota PKK.

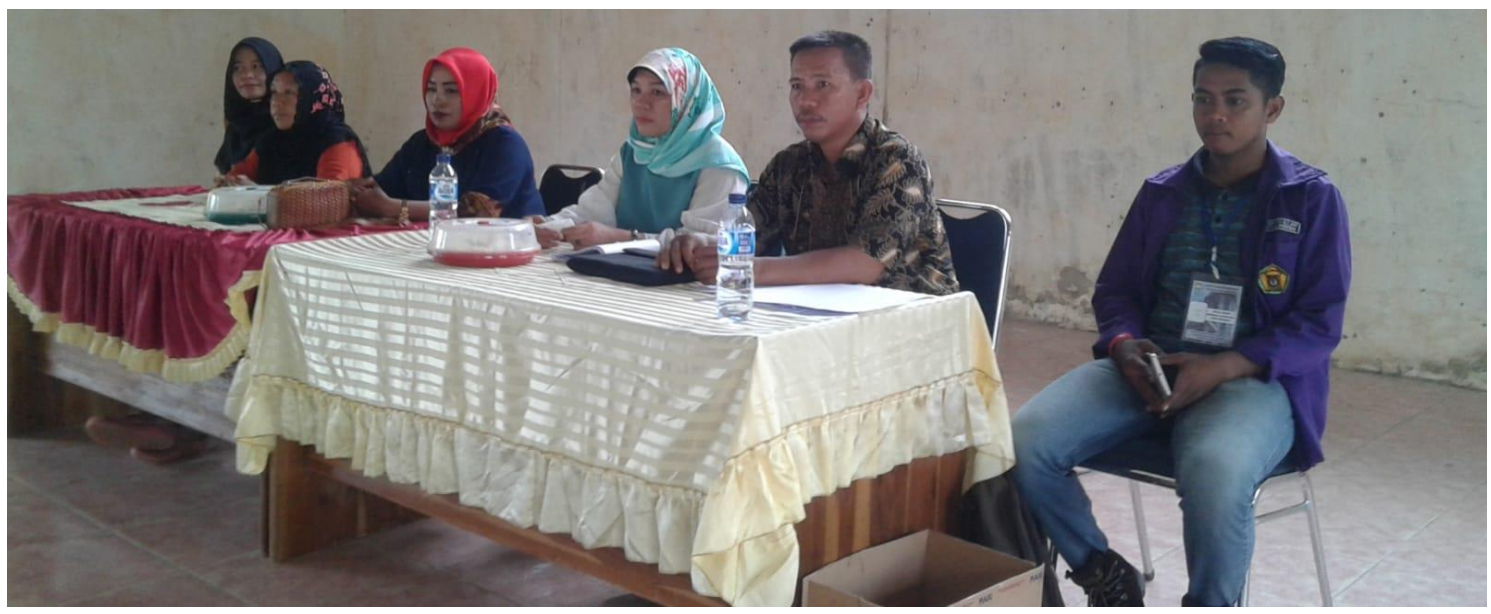

Gambar 1. Tim penyuluhan kewirausahaan dari LPPM Unilaki dan Mahasiswa

Pelaksanaan penyuluhan kewirausahaan pada Kelompok Ibu PKK Desa Rambu-Rambu melalui beberapa tahapan kegiatan yaitu pembukaan acara, sambutan Kepala Desa, perkenalan tim penyuluh dan dilanjutkan dengan penyampaian materi penyuluhan. Adapun pokok-pokok materi penyuluhan yang disampaikan oleh tim yakni gambaran kondisi kewirausahaan dan pelaku UMK di di Indonesia dan di Kabupaten Konawe Selatan, penjelasan konsep wirausaha dan kewirausahaan, tujuan dan manfaat berwirausaha, konsep UMK, penjelasan tentang hambatan dan resiko yang sering dihadapi pelaku UMK, penjelasan potensi desa yang dapat dijadikan peluang UMK, menjelaskan potensi unggulan desa menjadi produk unggulan desa, penjelasan terkait pentingnya usaha peningkatan pendapatan keluarga (UP2K), penjelasan terkait akses sumber pembiayaan UMK, dan penjelasan hubungan kewirausahaan dengan peningkatan kesejahteran dan peningkatan perekonomian desa yang sinergi dengan visi dan misi Kabupaten Konawe Selatan yaitu mewujudkan "Desa Maju Konsel Hebat" dalam pembangunan daerah Kabupaten Konawe Selatan.

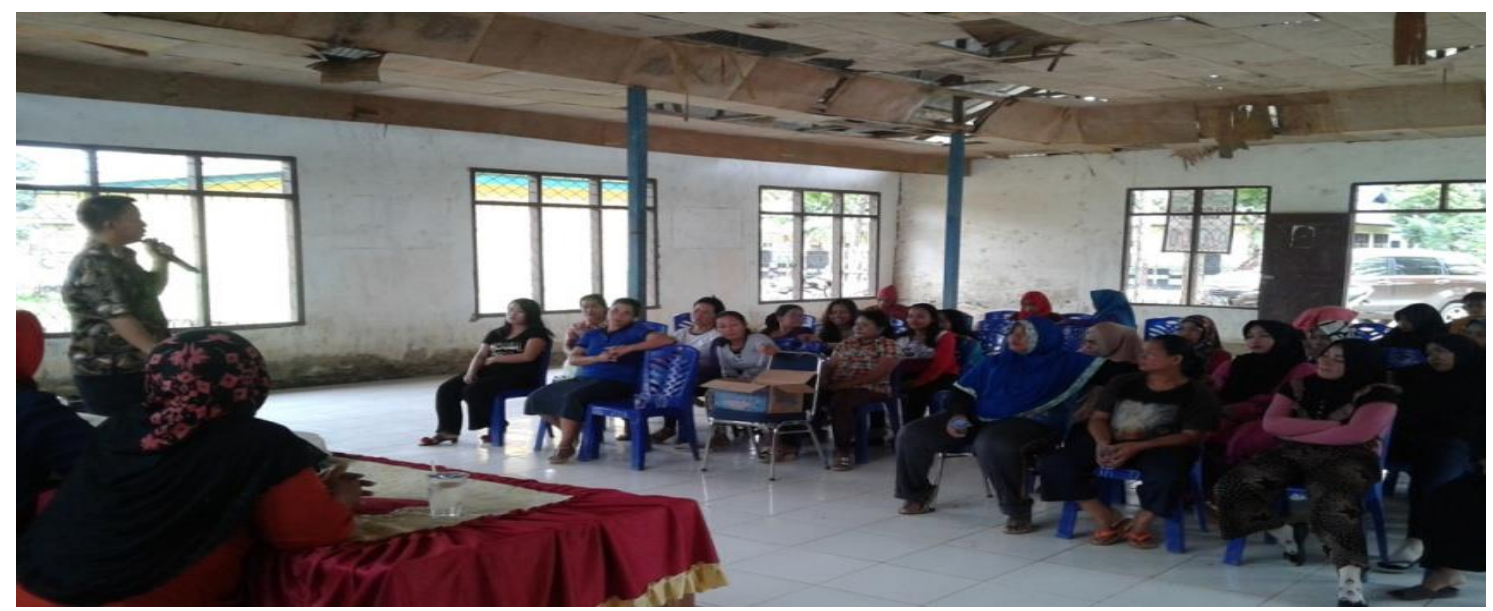

Gambar 2. Proses penyuluhan kewirausahaan pada kelompok ibu PKK 
Setelah penyampaian materi penyuluhan tersebut oleh tim penyuluh maka langkah kegiatan selanjutnya adalah sesi tanya jawab dengan peserta yang hadir untuk mengetahui pengetahuan, pemahaman serta respon peserta selama proses penyuluhan berlangsung. Berdasarkan hasil tanya jawab pelaksanaan penyuluhan kewirausahaan yang dilaksanakan oleh LPPM Universitas Lakidende Unaaha dengan menugaskan tim dari Dosen Fakultas Ilmu Adminsitrasi sebagai pemateri dalam penyuluhan dapat diketahui bahwa respon anggota PKK sangat antusias, semangat dan termotivasi serta kegiatan penyuluhan sangat bermanfaat karena belum pernah ada penyuluhan.

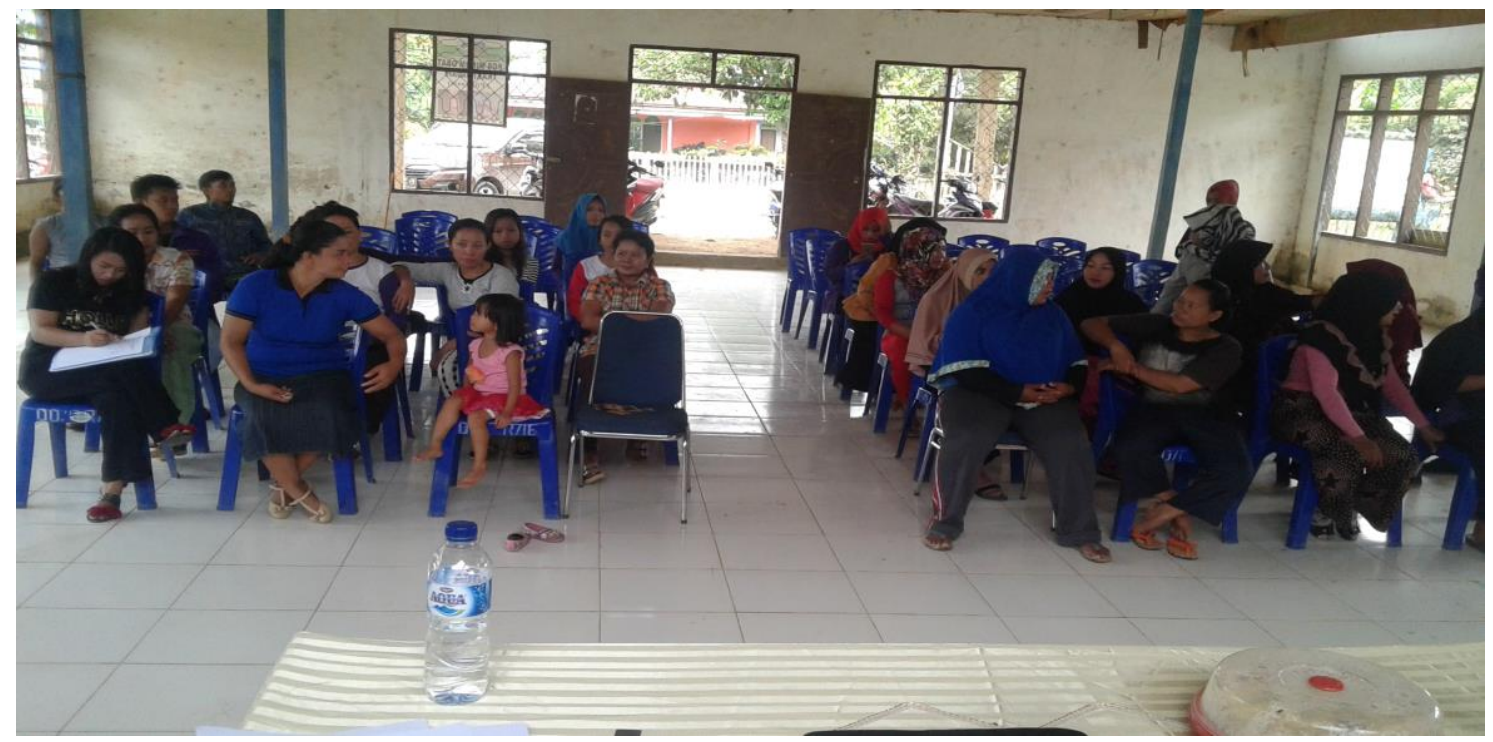

Gambar 3. Peserta penyuluhan ibu PKK Desa Rambu-Rambu.

Berdasarkan tanya jawab yang dilakukan dalam penyuluhan diperoleh informasi bahwa anggota PKK Desa Rambu Rambu sangat mendukung dan merasakan manfaatkan penyuluhan kewirausahaan. Dengan demikian melalui umpan balik informasi dari peserta diperoleh respon positif bahwa peserta dapat menambah wawasan pengetahuan dan pemahaman tentang kewirausahaan untuk meningkatkan pendapat dalam keluarga. Karena itu, pelaksanaan penyuluhan kewirausahaan mendapat memberi dampak positif dan dapat menjadi motivasi bagi anggota PKK Desa Rambu-Rambu Kecamatan Laeya untuk lebih inoatif. Kegiatan penyuluhan ini dapat mendorong Ibu PKK untuk menciptakan suatu usaha baru, seperti pendapat Peter F. Drucker kewirausahaan merupakan kemampuan dalam menciptakan sesuatu yang baru dan berbeda (Krisnaldy, 2021).

Dengan adanya informasi yang diterima anggota PKK melalui penyuluhan UMK maka dapat memberi motivasi, semangat dan minat untuk memanfaatkan sumber daya hasil pertanian dan perkebunan di desa seperti beras, ubi jalar, singkong, pisang, beras, sagu, berbagai macam sayuran dan lain sebagainya. Hal ini selaras dengan studi motivasi kewirausahaan, bahwa mahasiswa memiliki motivasi semangat, kreativitas, dan inovasi, berani mengambil risiko akan berminat untuk melakukan aktivitas berwirasusaha selama menjalani masa studi di kampus (Miranda, 2020). 


\section{Simpulan dan Tindak Lanjut}

Berdasarkan hasil kegiatan pengabdian kepada masyarakat tentang penyuluhan kewirausahaan pada kelompok PKK dalam mendorong pelaku UMK di Desa Rambu-Rambu dapat disimpulkan bahwa setelah mengikuti penyuluhan anggota PKK sebagai peserta memberi respon positif dan sangat antusias, karena informasi yang disampaikan sangat bermanfaat, dapat menambah wawasan dan pengetahuan cara berwirausaha. Melalui kegiatan penyuluhan pada anggota PKK dapat memberi motivasi untuk berwirausaha pada skala UMK. Selain itu, dapat mendorong tumbuhnya jiwa wirausaha (entrepreneur) untuk memanfaatkan sumber daya hasil pertanian dan perkebunan yang ada dan belum dimanfaatkan oleh warga Desa RambuRambu untuk menambah pendapatan dan peningkatan ekonomi keluarga.

Sehubungan dengan terbatasnya waktu pelaksanaan penyuluhan pada anggota PKK, maka tindak lanjut dari kegiatan penyuluhan kewirausahaan ini adalah akan dilaksanakan kegiatan pelatihan sesuai permintaan peserta yang hadir. Rencana kegiatan pelatihan akan difokuskan pada praktek pembuatan produk UMK dengan memanfaatkan hasil pertanian dan perkebunan yang ada di Desa Rambu Rambu. Anggota PKK akan dilatih membuat produk secara kreatif dan inovatif dari proses pembuatan sampai pada pembuatan branding serta pengemasan produk hasil praktek. Efek dari kegiatan tersebut diharapkan dapat menjadi salahsatu sumber peningkatan pendapatan keluarga.

\section{Daftar Pustaka}

Alma, B. (2014) Kewirausahaan untuk Mahasiswa dan Umum. Bandung: Alfabeta.

Apriani, A., Widayati, C.C., Wuryandari, N. E.R., \& Fathihani, (2021), Pelatihan Motivasi Dan Kewirausahaan Untuk Pkk Di Kelurahan Bojong Indah, Parung, Kabupaten Bogor, Jurnal Pengabdian Masyarakat (ANDHARA) E-ISSN : 2776-883X, Volume 1, Issue 2, November 2021, Page 36 - 43, http://jurnal.undira.ac.id/index.php/jpmk

Krisnaldy, Saepudin, A., Wibowo, T., Ainaink, N., Ridwan, N. A., \& Hidayat, L., (2021) (Pelatihan Menjadi Wirausaha Di Masa Pandemi Covid19 Bagi Ibu PKK, Abdi Laksana Jurnal Pengabdian Kepada Masyaraka, Volume 2 Nomor 2 (2021), Page 320-326, DOI: 10.32493/al-jpkm.v2i2.10504

Miranda, J., Fatira, M., \& Zuhirsyan, M., (2020) Entrepreneurial Motivation of Islamic Young Generation, Journal of Trends Economics and Accounting Research, Vol 1, No 2, Desember 2020, pp 51-60, Website https://journal.fkpt.org/index.php/jtear

Siagian, S.P.,(2012).Manajemen Sumber Daya Manusia. Jakarta. Bumi Aksara.

Tambunan, T. (2012), Usaha Mikro Kecil dan Menengah di Indonesia. Jakarta: LP3ES.

Tuwu, D. (2018). Peran Pekerja Perempuan Dalam Memenuhi Ekonomi Keluarga: Dari Peran Domestik Menuju Sektor Publik. Al Izzah: Jurnal Hasil-Hasil Penelitian-ISSN: 1978-9726. Volume 13, Nomor 1.DOI: http://dx.doi.org/10.31332/ai.v13i1.872 
Vernia, D.M., Suprapto, H. A. \& Supandi, A., (2018) Penyuluhan Pentingnya Minat Kewirausahaan Dalam Membentuk Karakter Mandiri Siswa Smk Insan Mulia Dan SMP Azzuhriyah Kota Bekasi, MATAPPA: Jurnal Pengabdian Kepada Masyarakat, Volume 1 | Nomor 2 | September | 2018, 54-59, DOI: http://dx.doi.org/10.31100/matappa.v1i2.103

Yonaldi, S. (2018), Kewirausahaan Bagi Industri Kecil Menengah Di Kota Padang Dalam Rangka Peningkatan Kemampuan Manajemen Dan Perluasan Pasar, Jurnal Pengabdian Kepada Masyarakat Dewantara, Volume 1, Nomor 1, September 2018., 8 -26

DOI: https://doi.org/10.31317/jpmd.v1i1\%20Septembe.319 